\title{
Basal Metabolism during Recovery from Severe Undernutrition
}

\author{
By J. BEATTIE and PHILIPPA H. HERBERT (Leverhulme Scholar) \\ Bernhard Baron Research Laboratories, Royal College of Surgeons of \\ England, Lincoln's Inn Fields, London, W.C. 2
}

(Received 31 fuly 1947)

The studies reported below were made on two groups of individuals who had suffered severe restriction of food intake over periods of not less than 6 months and extending in some over I year. Group I comprised severely emaciated adults of both sexes, a high proportion of them elderly, admitted to hospital in The Hague, Holland, during the months of May and June I945. Weight losses in this group ranged from I2 to $3 \mathrm{I} \cdot 5 \mathrm{~kg}$. Detailed diet histories were not obtained, but it is probable that, during the first 3 months of 'famine' conditions, the daily calorie intake did not exceed I600 Cal., and during the subsequent and last 3 months it may not have exceeded 1000. Of the seventeen patients studied in this group six have been discarded, either because no reliable estimate of their normal body-weights was available, or because it was not possible to obtain satisfactory and reproducible oxygen-consumption records. Group II contained, with one exception, young adult males who had been detained in a German civil prison for over 12 months. During this period the daily ration provided an average intake of not more than $175^{\circ} \mathrm{Cal}$./day. When they came under observation they were from II 7 to $24 . \mathrm{kg}$. under their normal weights. With the exception of some intermittent diarrhoea in Group I, all the subjects were found to be free from organic disease.

\section{EXPERIMENTAL \\ Methods}

Determinations of oxygen consumption were made $13^{-15} \mathrm{hr}$. after the last meal, which contained less than one-fifth of the total daily intake. Subjects were under 'basal' conditions. Determinations in Group I were made with a Knipping apparatus and in Group II with the standard Benedict spirometer. Two or more Io min. recordings of oxygen consumption were made. Values were accepted when two successive determinations agreed within $\pm 5 \%$. The lower value was taken as the basal value.

The heat productions were calculated from the oxygen-consumption values by assuming an R.Q. of 0.82 which gives a calorific value of $4.825 \mathrm{Cal}$./1. of oxygen. As Beattie \& Herbert (1947) have pointed out that heat production/sq.m. does not provide a true index of the metabolic rate when there is considerable body-weight loss, all heat production values have been expressed as Cal. $/ \mathrm{kg}$. $/$ day. A normal value for each 
subject has been calculated by taking the standard heat production/sq.m. for the appropriate age and sex (Boothby \& Sandiford, 1929) and multiplying this by the surface area computed from the weight and height by the formula of $\mathrm{Du}$ Bois \& Du Bois (Igr6). The value so obtained was multiplied by 24 and then divided by the normal body-weight. A $5 \%$ deduction from the standard heat production has been made to compensate for 'training' in these subjects, and a further deduction of $5 \%$ when the age exceeded 55 years. Du Bois (1936) has discussed the need for such corrections in his review of normal standards suggested by various observers.

All subjects were free from oedema or had at most a slight trace of oedema around the ankles at the time of the first oxygen-consumption test.

\section{Dietary history}

The dietary histories of the subjects in the two groups differed considerably. The first four subjects in Group I were admitted to hospital for extreme weakness owing to prolonged food deprivation. The diet before admission probably contained not more than I000 Cal./day over a period of some weeks and may have been as low as $500 \mathrm{Cal}$. The remainder of Group I was admitted for the same reason, but these subjects had had access for a period of 10-14 days to a ration which was somewhat higher than I $500 \mathrm{Cal}$. but probably did not exceed $2000 \mathrm{Cal}$. These estimates of previous dietary history have to be treated with some reserve but, if anything, they tend to be on the generous side (Burger, Sandstead \& Drummond, 1945). Group II, on the other hand, had a much more reliable dietary history. As they were inmates of a German civil prison their dietary scales were known with some accuracy from about I July 1945 . All the subjects in this group were in this prison at that date. Between I July 1945 and I February 1946 the standard prison ration was $155^{\circ}$ Cal. Study of the quantities of food supplied and consumed in the prison over this period led to the conclusion that this average ration was not exceeded. About I February the standard ration was reduced to I roo Cal. Supplies of potatoes from prison-farm stocks were used to supplement the ration but by not more than $150 \mathrm{Cal}$./day. The ration was improved to the previous standard of $\mathrm{I} 55^{\circ}$ Cal. about I May. Observation of actual intakes for a period of 6 weeks before balance studies and oxygen-consumption tests were made revealed that these subjects were getting a daily ration of around $175^{\circ} \mathrm{Cal}$. The difference between the standard prison ration of $155^{\circ}$ and the actual ration of $175^{\circ}$ Cal. was made up by extra allowances of bread and potatoes provided either from prisonfarm stocks or by the local German food authorities. To sum up, the first four subjects in Group I had had an average daily ration of not more than $1000 \mathrm{Cal}$. before they came under observation, the remainder of this group, an average ration of between 1500 and 2000 Cal., while all in Group II had been receiving an average ration of $175^{\circ}$ Cal.

\section{Observations}

The data used in computing the normal rate of heat production $/ \mathrm{kg}$. body-weight are given in Table $\mathrm{r}$. Observed values for oxygen consumption and heat production $/ \mathrm{kg}$. have been set out in Table 2. In Table 3 the calorie and nitrogen intakes for the day 
Table I. Calculated heat production in the normal state of two groups of emaciated subjects

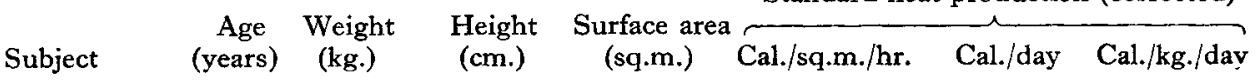
Group I (Dutch):

\begin{tabular}{|c|c|c|c|c|c|c|c|}
\hline v. A. & 57 & 74.5 & 169 & $1 \cdot 84$ & $33 \cdot I$ & 1460 & $19 \cdot 6$ \\
\hline T. Jr. & $2 I$ & 72 & 190 & $x \cdot 97$ & $3^{8 \cdot 9}$ & 1840 & $25 \cdot 6$ \\
\hline v. d. H. & 36 & 55 & 165 & $I \cdot 59$ & $37 \cdot 2$ & 1420 & $25 \cdot 8$ \\
\hline d. G. & 58 & 70 & 170 & $I \cdot 80$ & $33 \cdot I$ & $143^{\circ}$ & 20.4 \\
\hline B. & 45 & 73 & 176 & $\mathrm{I} \cdot 88$ & 35.9 & 1620 & $22 \cdot 2$ \\
\hline Z. (F) & 62 & 67 & 164 & $I \cdot 72$ & $32 \cdot 5$ & 1340 & 20.0 \\
\hline E. & 36 & 76 & I75 & $I \cdot 9 I$ & $37 \cdot 2$ & 1710 & 22.5 \\
\hline J. & 59 & $5^{6}$ & 165 & $I .60$ & $33^{\cdot I}$ & 1270 & $22 \cdot 7$ \\
\hline V. $(F)$ & 66 & 65 & I 54 & $x \cdot 62$ & $30 \cdot I$ & 1170 & 18.0 \\
\hline Bg. & 74 & 95 & I83 & $2 \cdot 18$ & $29 \cdot 6$ & $155^{\circ}$ & $16 \cdot 3$ \\
\hline W. & 62 & $5^{8}$ & 152 & I.53 & $32 \cdot 5$ & 1190 & $20 \cdot 6$ \\
\hline \multicolumn{8}{|c|}{ Group II (German): } \\
\hline Ks. & 21 & $7 \pi$ & I $8 \mathrm{I}$ & $1 \cdot 90$ & $38 \cdot 9$ & 1780 & $25{ }^{\circ} 0$ \\
\hline Lv. & 25 & 73 & 184 & $I \cdot 94$ & $3^{8 \cdot 1}$ & I 780 & 24.4 \\
\hline KI. & 22 & 65 & 168 & $x \cdot 73$ & $38 \cdot 9$ & 1620 & 24.9 \\
\hline Wz. & 27 & $71 \cdot 5$ & 169 & $I \cdot 84$ & $3^{8 \cdot 1}$ & 1690 & 23.7 \\
\hline Sc. & 25 & 69 & 166 & $\mathrm{I} \cdot 92$ & $3^{8 \cdot 1}$ & 1760 & $25 \cdot 6$ \\
\hline Gm. & 21 & 70.5 & 165 & I.77 & $38 \cdot 9$ & $165^{\circ}$ & 23.5 \\
\hline Gt. & 24 & 73 & 170 & $1 \cdot 83$ & $3^{8 \cdot 9}$ & 1710 & 23.4 \\
\hline Rs. & $2 \mathrm{r}$ & 67 & I7I & I. 78 & $38 \cdot 9$ & 1660 & 24.8 \\
\hline Gd. & $3 \mathrm{I}$ & 69 & 170 & I.79 & $37 \cdot 8$ & 1620 & $23 \cdot 6$ \\
\hline $\mathrm{Bm}$ & 25 & 65 & 167 & $I \cdot 72$ & $3^{8 \cdot x}$ & 1580 & 243 \\
\hline Ru. & 52 & 70 & 170 & $I \cdot 80$ & $35 \cdot 3$ & 1530 & $2 \mathrm{x} \cdot 8$ \\
\hline
\end{tabular}

(F) Indicates female subject.

Table 2. Observed heat production in the emaciated state of two groups of emaciated subjects

\begin{tabular}{|c|c|c|c|c|c|c|}
\hline \multirow[b]{2}{*}{ Subject } & \multirow[b]{2}{*}{$\begin{array}{l}\text { Weight } \\
\text { (kg.) }\end{array}$} & \multirow{2}{*}{$\begin{array}{c}\text { Oxygen } \\
\text { consumption } \\
(1 . / \mathrm{hr} .)\end{array}$} & \multicolumn{2}{|c|}{ Heat production } & \multirow{2}{*}{$\begin{array}{c}\text { Change in } \\
\text { heat } \\
\text { production } \\
\text { from normal } \\
(\%)\end{array}$} & \multirow{2}{*}{$\begin{array}{c}\text { Fall in } \\
\text { body-wt. } \\
(\%)\end{array}$} \\
\hline & & & Cal./day & Cal./kg./day & & \\
\hline \multicolumn{7}{|c|}{ Group I (Dutch): } \\
\hline v. A. & $46 \cdot I$ & II $\cdot 3$ & 1300 & $28 \cdot 3$ & +44 & $3^{8}$ \\
\hline T. Jr. & $45^{\circ} 0$ & $9 \cdot 2$ & 1060 & $23 \cdot 6$ & -8 & $3^{8}$ \\
\hline v. d. H. & 40.9 & $7 \cdot 3$ & 840 & $20 \cdot 5$ & -20 & 26 \\
\hline d. G. & $49 \cdot 1$ & $7 \cdot 7$ & 890 & $18 \cdot I$ & $-I I$ & 30 \\
\hline B. & $58 \cdot 0$ & 13.7 & 1590 & $27 \cdot 4$ & +23 & $2 I$ \\
\hline Z. (F) & $44^{\circ} \circ$ & $\mathrm{II} \cdot 8$ & 1360 & 30.9 & +55 & 35 \\
\hline E. & $55 \cdot 3$ & $\mathrm{II}_{4}$ & 1320 & $23 \cdot 8$ & +6 & 27 \\
\hline J. & 40.0 & 14.0 & 1620 & 40.6 & +79 & 29 \\
\hline V. (F) & $46 \cdot 3$ & $10 \cdot \mathrm{I}$ & 1170 & 25.3 & +40 & 29 \\
\hline Bg. & $66 \cdot 2$ & 13.5 & 1560 & $23 \cdot 6$ & +45 & 30 \\
\hline W. & $46 \cdot 0$ & $10 \cdot 7$ & 1240 & $26 \cdot 9$ & +31 & 26 \\
\hline \multicolumn{7}{|c|}{ Group II (German): } \\
\hline Ks. & $55 \cdot 5$ & $12 \cdot 6$ & 1460 & $26 \cdot 3$ & +5 & 22 \\
\hline Lv. & $55^{\circ} 0$ & $12 \cdot 2$ & 1410 & $25 \cdot 3$ & +4 & 25 \\
\hline $\mathrm{Kl}$. & 53.2 & $9 \cdot 4$ & 1080 & $20 \cdot 2$ & -19 & 18 \\
\hline Wz. & $53 \cdot 8$ & $x \cdot 9$ & 1370 & 25.5 & +8 & 25 \\
\hline Sc. & $55 \cdot 7$ & 10.7 & 1240 & $22 \cdot 2$ & -13 & 19 \\
\hline $\mathrm{Gm}$. & 50.1 & 9.7 & 1120 & 22.4 & -5 & 29 \\
\hline Gt. & $48 \cdot 9$ & $8 \cdot 8$ & 1020 & $20 \cdot 9$ & -11 & 33 \\
\hline Rs. & $55 \cdot 3$ & 12.4 & 1430 & 25.9 & +4 & 17 \\
\hline Gd. & 45.5 & $8 \cdot 8$ & 1020 & $22 \cdot 4$ & -5 & 34 \\
\hline $\mathrm{Bm}$. & 47.9 & $9 \cdot 7$ & rizo & 23.5 & -3 & 26 \\
\hline Ru. & $53 \cdot 6$ & $I I \cdot 2$ & 1290 & $24 \cdot 1$ & $+I I$ & 23 \\
\hline
\end{tabular}

(F) Indicates fèmale subject. 
before the test are shown both as total intake and intake $/ \mathrm{kg}$. These are compared with the calculated change in heat production $/ \mathrm{kg}$. These comparisons are shown graphically in Figs. $I$ and 2.

Table 3. Intakes of calories and protein (nitrogen) of two groups of emaciated subjects on the day preceding the (first) test summarized in Table 2

\begin{tabular}{|c|c|c|c|c|}
\hline \multirow[b]{2}{*}{ Subject } & \multicolumn{2}{|c|}{ Calories } & \multicolumn{2}{|c|}{ Nitrogen } \\
\hline & Total & Cal./kg. & Total (g.) & g. $/ \mathrm{kg}$. \\
\hline \multicolumn{5}{|c|}{ Group I (Dutch): } \\
\hline $\begin{array}{l}\text { v. A. } \\
\text { T. Jr. }\end{array}$ & $\begin{array}{l}2830 \\
2000\end{array}$ & $\begin{array}{l}6 r \cdot 4 \\
48 \cdot 8\end{array}$ & $\begin{array}{r}13 \cdot 4 \\
8 \cdot 3\end{array}$ & $\begin{array}{l}0.29 \\
0.18\end{array}$ \\
\hline v. d. H. & II70 & $28 \cdot 7$ & $6 \cdot 0$ & 0.15 \\
\hline d. G.. & I 320 & 27.0 & 9.9 & 0.20 \\
\hline B. & $355^{\circ}$ & $6 r \cdot 3$ & $34 \cdot 8$ & 0.60 \\
\hline Z. (F) & 2990 & $68 \cdot 0$ & $25 \cdot 5$ & 0.58 \\
\hline E. & 2320 & $42 \cdot 0$ & $8 \cdot 3$ & $0 \cdot 15$ \\
\hline $\mathrm{J}$ & $317^{\circ}$ & $79 \cdot 2$ & $49 \cdot 9$ & $1 \cdot 25$ \\
\hline V. $(F)$ & 2980 & $64 \cdot 4$ & $25 \cdot 4$ & 0.55 \\
\hline Bg. & 2700 & $40 \cdot 8$ & $16 \cdot 7$ & 0.25 \\
\hline W. & 2020 & $43^{\cdot 8}$ & $30 \cdot 6$ & 0.66 \\
\hline \multicolumn{5}{|c|}{ Group II (German): } \\
\hline Ks. & 1870 & $33 \cdot 8$ & 10.0 & 0.18 \\
\hline Lv. & 2170 & $39 \cdot 5$ & $x+0$ & 0.20 \\
\hline $\mathrm{Kl}$. & $155^{\circ}$ & $29 \cdot 2$ & $5 \cdot 9$ & 0.11 \\
\hline Wz. & 2260 & $42 \cdot 1$ & $8 \cdot 6$ & 0.16 \\
\hline Sc. & I780 & $3 \mathrm{I} \cdot 9$ & $9 \cdot 5$ & 0.17 \\
\hline Gm. & 2140 & $42 \cdot 8$ & $8 \cdot 5$ & 0.17 \\
\hline Gt. & I $55^{\circ}$ & $3 \mathrm{I} \cdot 8$ & $5 \cdot 9$ & 0.12 \\
\hline Rs. & 1830 & $33 \cdot I$ & $10 \cdot 0$ & 0.18 \\
\hline Gd. & 1770 & $38 \cdot 9$ & $9 \cdot 6$ & 0.21 \\
\hline $\mathrm{Bm}$. & 1660 & $34 \cdot 6$ & $12 \cdot 0$ & 0.25 \\
\hline Ru. & 1820 & $34 \cdot 0$ & $9 \cdot I$ & 0.17 \\
\hline
\end{tabular}

(F) Indicates female subject.

In many of the subjects oxygen-consumption tests were repeated at intervals during the period of observation, usually when calorie and nitrogen intakes were altered. In Group I these tests could only be repeated at relatively long intervals, consequently individual observations have been shown in Table 4. In Group II, where oxygenconsumption tests were repeated at intervals not exceeding 3 days, the mean value of the heat production for each dietary period has been given. In calculating intakes and heat productions $/ \mathrm{kg}$., the mean body-weight over the dietary period has been used. The change in body-weight over each period has been given (Table 5). It will be noted that not all subjects in the series are included in Tables 4 and 5. Omissions from Table 4 are due to the fact that observations after the first test were not made because the subject concerned was removed from the study series. This was due to the onset of a form of diarrhoea of unknown origin which interfered with the experiments. In Table 5 certain subjects included in Tables $1-3$ have been omitted because they were discharged from the institution where the experimental work was being done before further records could be made. 
The values for heat production $/ \mathrm{kg}$. body-weight, at the time of the first oxygenconsumption test, showed surprisingly few values below the normal level. These values, it must be emphasized, were obtained within 3 days after the first known intake had been given. Consequently they must be regarded as the reaction to that

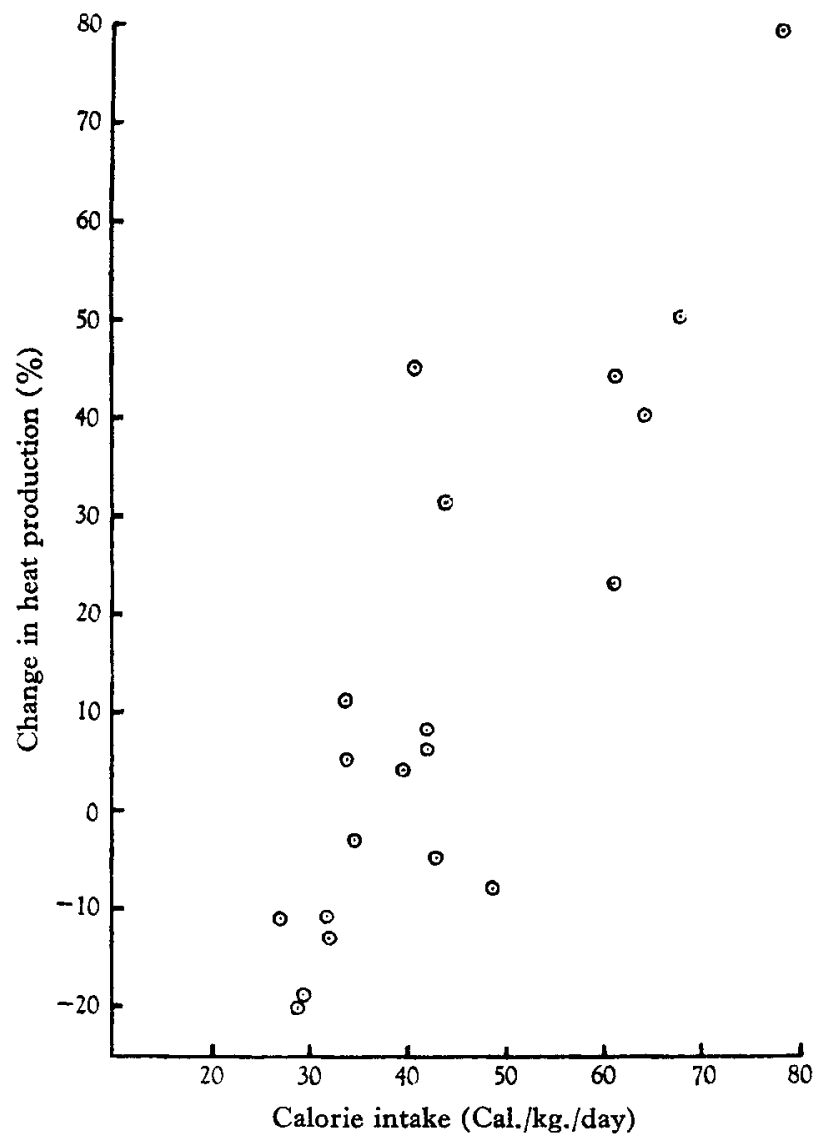

Fig. I. Percentage change from the normal level in heat production $/ \mathrm{kg}$. body-weight of emaciated subjects on different calorie intakes $/ \mathrm{kg}$. body-weight.

intake. When the relation between the calorie intake (Cal./kg.) and the change in heat production/kg. (Fig. I) is shown graphically, the percentage change in heat production is seen to increase proportionally with increased calorie intake. At a calorie intake level of about $35 \mathrm{Cal} . / \mathrm{kg}$./day the heat production $/ \mathrm{kg}$. is at the normal level. The relation between nitrogen intake and percentage change in heat production is not direct (Fig. 2). At levels around $0.2 \mathrm{~g}$. N/kg./day the calorie intake is apparently the determining factor. At intake levels above $0.2 \mathrm{~g}$. N, calories again would appear to determine the change in heat production.

These rates of heat production $/ \mathrm{kg}$. were those obtained within 3 days of the start of a controlled and, for many subjects, considerably richer diet, both in calories and protein, than their ration before they came under observation and treatment. When 
dietetic treatment continued over a period of $3-4$ weeks, the level of heat production ceased to be related closely to the level of calorie intake. This is apparent from Table 4 (Dutch series) and from Fig. 3 .

In the German series the calorie intakes were for several reasons varied over a much narrower range than in the Dutch series. The oxygen-consumption tests were carried out at intervals of $2-3$ days and the mean values for heat production for the tests in

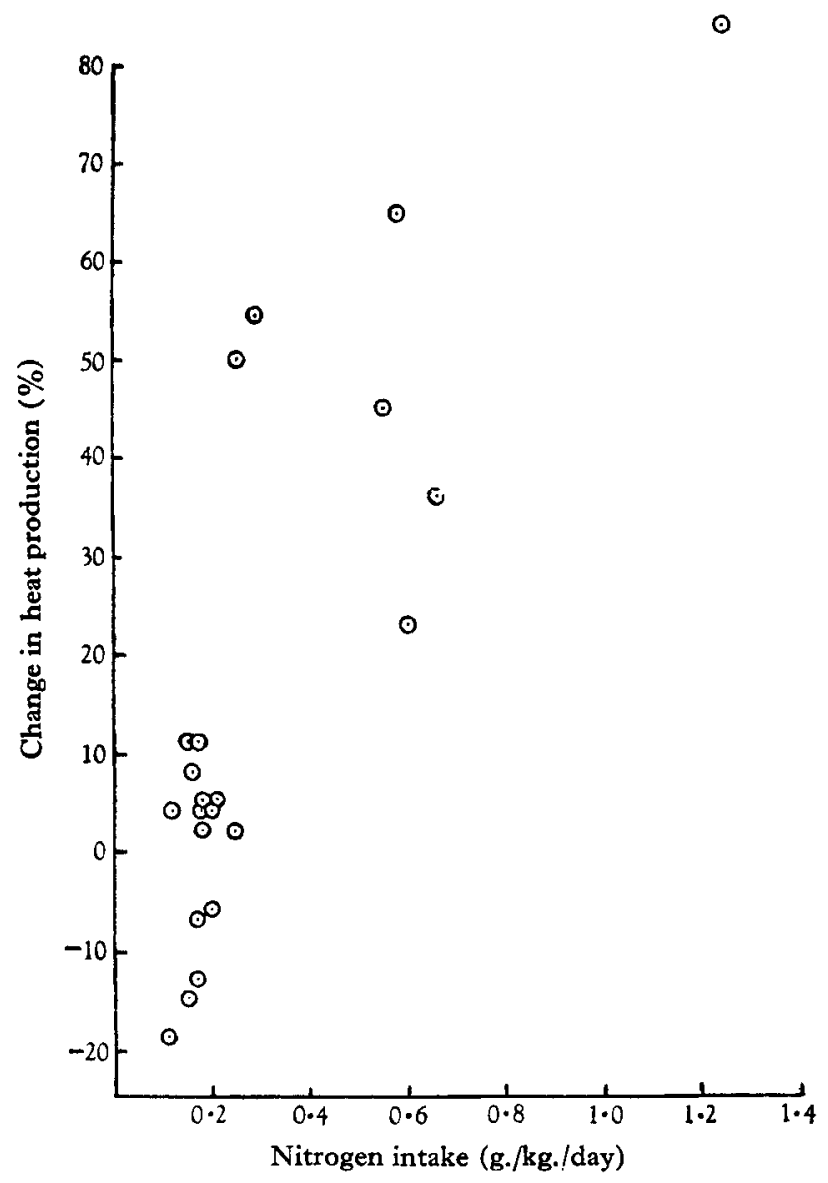

Fig. 2. Percentage change from the normal level in heat production $/ \mathrm{kg}$. body-weight of emaciated subjects in relation to their nitrogen intake.

each diet period have been used to calculate the change in heat production from the normal level (Table 5). With one exception (K1.), the final level of heat production was either at or below the initial level, and that in spite of an increase in calorie intake of $800 \mathrm{Cal}$. It seemed that on an intake of $253^{\circ} \mathrm{Cal}$./day, or between $43 \cdot 8$ and $48 \cdot 7 \mathrm{Cal} / \mathrm{kg}$., the tendency was for heat production to fall to about $10 \%$ below the normal level (range $-\mathrm{I}_{4}$ to -5 ). The changes in heat production from normal were not related directly to the calorie intake/kg. (Fig. 4). 
DISCUSSION

Our data suggest two phases in basal metabolism during recovery from starvation. The first or immediate phase is apparently a result of the calorie intake on the day or days preceding the first oxygen-consumption determination and in it the level of heat production is related to the calorie intake. The second phase occurs later when there

Table 4. Individual values for heat production and intake of calories on days preceding the measurements of Group I (Dutch) of emaciated subjects during recovery

\begin{tabular}{|c|c|c|c|c|c|c|c|}
\hline \multirow[b]{3}{*}{ Subject } & \multirow{3}{*}{$\begin{array}{c}\text { Days } \\
\text { after } \\
\text { admission }\end{array}$} & \multirow{3}{*}{$\begin{array}{c}\text { Weight } \\
\text { (kg.) }\end{array}$} & & & \multicolumn{3}{|c|}{ Heat production } \\
\hline & & & \multicolumn{2}{|c|}{ Intake } & \multicolumn{3}{|r|}{ Change from } \\
\hline & & & Cal./day & Cal. $/ \mathrm{kg} . /$ day & Cal./day & Cal./kg./day & $(\%)$ \\
\hline \multirow[t]{3}{*}{ v. A. } & 3 & $46 \cdot x$ & 2830 & $6 I \cdot 4$ & 1305 & $28 \cdot 3$ & +44 \\
\hline & 13 & $45^{\circ} 2$ & $335^{\circ}$ & $74 \cdot I$ & I 369 & $30 \cdot 3$ & +55 \\
\hline & 24 & $46 \cdot 0$ & 3340 & $72 \cdot 7$ & 1563 & 34.0 & +73 \\
\hline \multirow[t]{3}{*}{ T. Jr. } & 3 & $45^{\circ} \circ$ & 2200 & $48 \cdot 8$ & 1062 & $23 \cdot 6$ & -8 \\
\hline & 12 & $45^{\cdot 2}$ & $223^{\circ}$ & $49 \cdot 3$ & I I 74 & 26.0 & +2 \\
\hline & 23 & $46 \cdot I$ & 3520 & $71 \cdot 2$ & 1271 & $27 \cdot 6$ & +8 \\
\hline \multirow[t]{2}{*}{ v. d. H. } & 3 & $40 \cdot 9$ & II 70 & $28 \cdot 7$ & 840 & 20.5 & -20 \\
\hline & 20 & $42 \cdot 2$ & 3240 & $76 \cdot 9$ & I 188 & $28 \cdot 2$ & +9 \\
\hline \multirow[t]{2}{*}{ d. G. } & 3 & $49^{\prime} I$ & 1330 & $27 \cdot 0$ & 890 & $18 \cdot I$ & $-\mathbf{I I}$ \\
\hline & 20 & $52 \cdot 3$ & FD & - & I209 & $23 \cdot 1$ & +13 \\
\hline \multirow[t]{2}{*}{ Z. (F) } & 2 & $44 \cdot 0$ & 2990 & $68 \cdot 0$ & 1360 & 30.9 & +55 \\
\hline & 14 & $46 \cdot 4$ & 2990 & $64 \cdot 5$ & 1271 & $28 \cdot 0$ & +40 \\
\hline \multirow[t]{4}{*}{ E. } & $\mathbf{I}$ & $55 \cdot 3$ & 2320 & $42 \cdot 0$ & 1318 & $23 \cdot 8$ & +6 \\
\hline & 13 & $55^{\cdot 6}$ & 2990 & $53 \cdot 8$ & 1202 & $2 I \cdot 6$ & -4 \\
\hline & 22 & $57 \cdot 6$ & 3170 & $55^{\circ} \circ$ & 1765 & 30.7 & +36 \\
\hline & $3 r$ & $63 \cdot 2$ & $\mathbf{F D}$ & - & 1702 & $27 \cdot 0$ & +20 \\
\hline \multirow[t]{5}{*}{ J. } & 2 & $40 \cdot 0$ & 3170 & $79 \cdot 2$ & 1623 & $40 \cdot 6$ & +79 \\
\hline & 13 & $41 \cdot 8$ & 3170 & $75 \% 7$ & 1327 & $3 I \cdot 8$ & +40 \\
\hline & 20 & $42 \cdot 0$ & $285^{\circ}$ & $67 \cdot 7$ & 1417 & 33.7 & +48 \\
\hline & 24 & 40.5 & 2260 & 55.8 & I $25^{8}$ & $3 I \cdot I$ & +37 \\
\hline & $3 I$ & $47 \cdot 2$ & FD & $\longrightarrow$ & 1619 & $34 \cdot 3$ & $+5 I$ \\
\hline \multirow[t]{3}{*}{$\mathrm{Bg}$. } & 2 & $66 \cdot 2$ & 2700 & 40.8 & I 563 & $23 \cdot 6$ & +45 \\
\hline & 8 & $65 \cdot 3$ & 2650 & $40 \cdot 7$ & 1401 & $2 I \cdot 4$ & $\begin{array}{r}45 \\
+30\end{array}$ \\
\hline & I 6 & $68 \cdot 5$ & FD & - & 1969 & $28 \cdot 8$ & +77 \\
\hline
\end{tabular}

(F) Indicates female subject.

FD Indicates a free diet which exceeded 3500 , and reached $5000 \mathrm{Cal}$. in some subjects.

ceases to be any close relationship between calorie intake and heat production $/ \mathrm{kg}$. In the German series the rate of heat production tended to be lower during the final diet period than during the first period in spite of a higher calorie intake in the final period. As we have assumed a constant R.Q. and, therefore, a constant calorie value for the oxygen consumed during the basal test period's, the observed changes in heat production $/ \mathrm{kg}$. are directly proportional to the oxygen entering the body through the lungs. In the first phase of recovery there is little doubt that the rate at which oxygen was entering the organism indicated the rate at which oxygen was being utilized by the body tissues. The remarkably high levels of oxygen uptake on high calorie intakes preceding the first basal oxygen-consumption test demonstrate that the first response 
of the undernourished subject to re-feeding is to catabolize foodstuffs rather than to conserve them.

The interpretation of the finding that some at least of the subjects were consuming less oxygen in the later phase even though the calorie intake was higher is not so clear. It may be that the fall in oxygen uptake by the body represents a true fall in the level

Table 5. Mean heat production and mean intake of calories on days preceding the measurements of Group II (German) of emaciated subjects during recovery

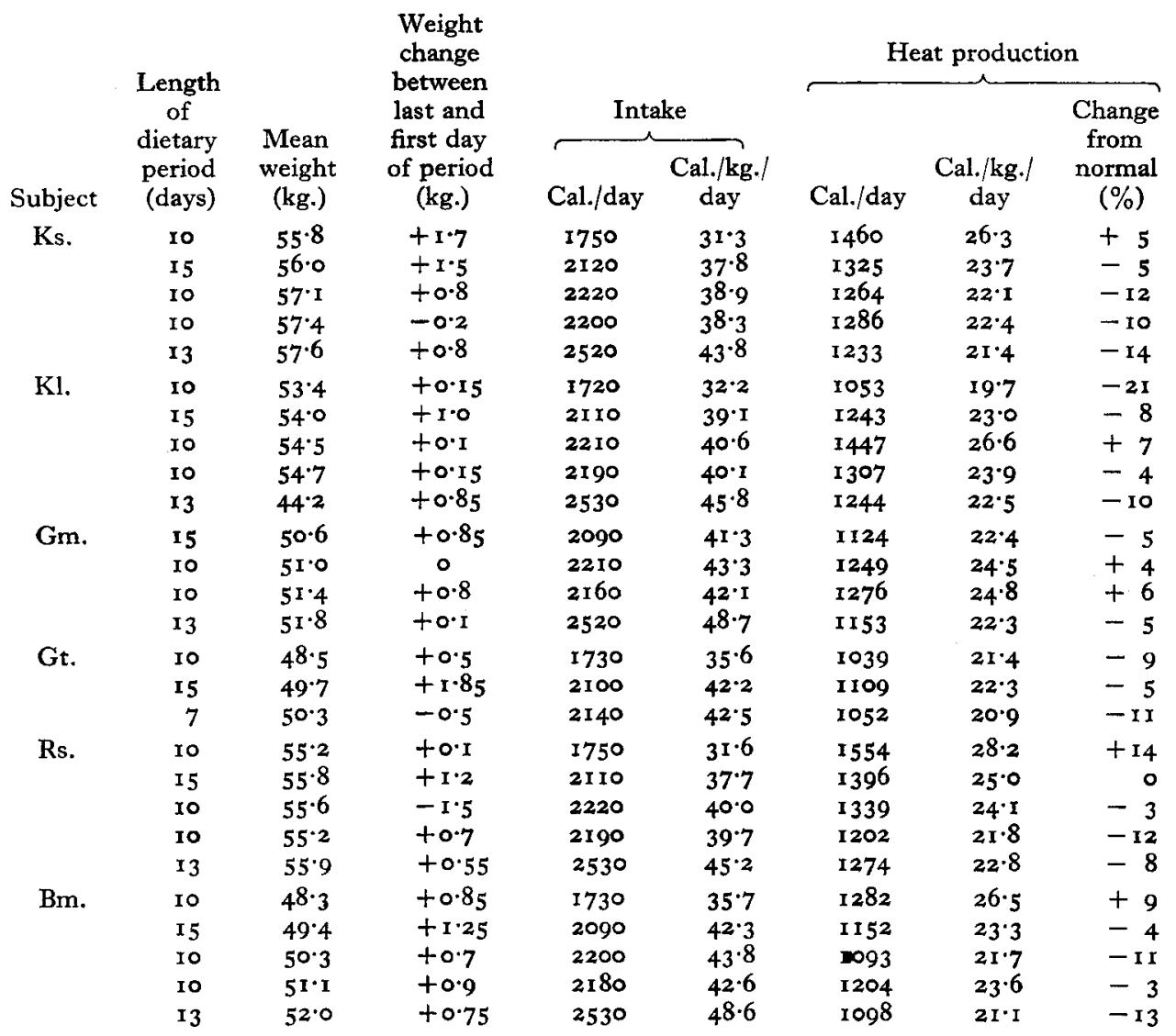

of oxygen utilization in the tissues, bringing this level below that found to prevail in the German group on the low calorie intakes of the first diet period. A second explanation may be that in the later phase relatively more carbohydrate than fat is being burned and the protein in the diet is being conserved and not burned as rapidly as in the first phase. The true R.Q. would, in such circumstances, rise, thus increasing the caloric value of the oxygen consumed. To compensate for the mean fall of $10 \%$ in oxygen consumption in the final diet period of the German group, the caloric value for the oxygen consumed would have to rise by $10 \%$ to bring. the heat production level up to that when the daily intake was around $175^{\circ} \mathrm{Cal}$., i.e. from

$$
4 \cdot 825 \text { to } 4 \cdot 825+0 \cdot 4825=5 \cdot 3075 \mathrm{Cal} . / 1 \text {. }
$$


This value is far in excess of the caloric value for oxygen when the R.Q. is I and would, if Lusk's (r928) formula relating caloric value and R.Q. holds true for values of the R.Q. above unity, require the R.Q. to be I.21. Such an R.Q. value would indicate that fat was being formed either from carbohydrate or protein or both.

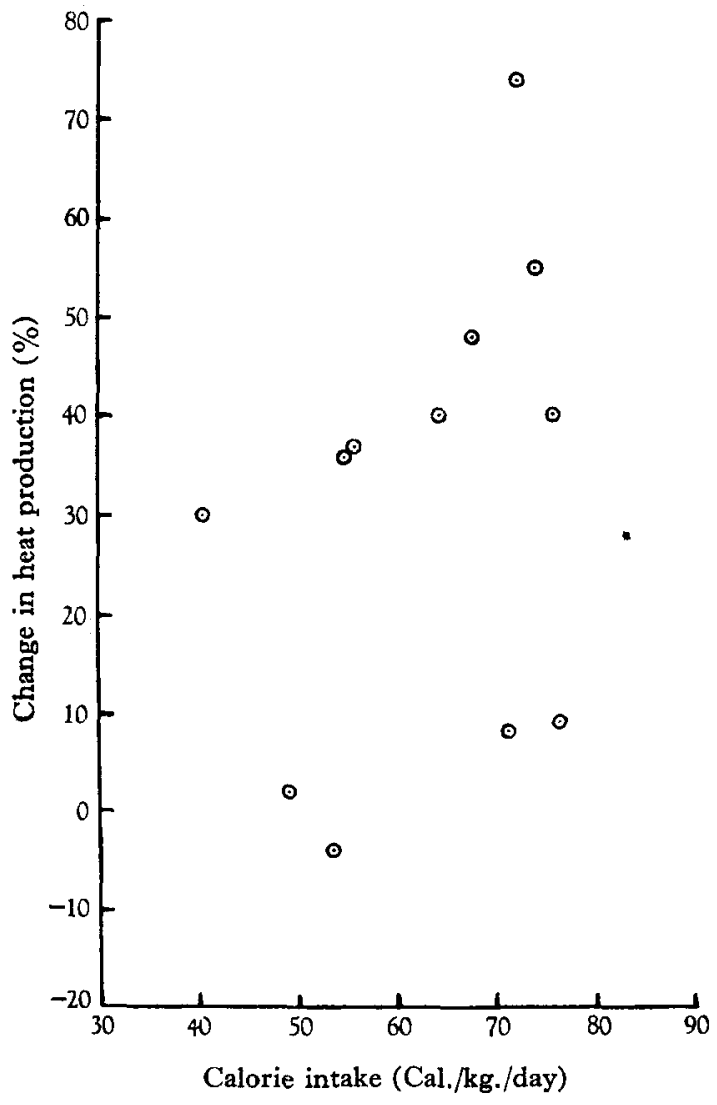

Fig. 3

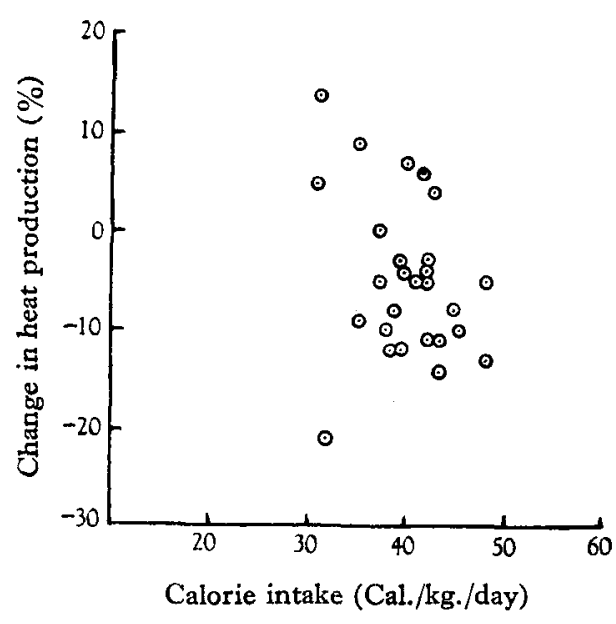

Fig. 4

Fig. 3. Percentage change from the normal level in heat production $/ \mathrm{kg}$. body-weight of emaciated subjects (Dutch group) during recovery, in relation to their calorie intake. The first observations recorded in Table 4 have been omitted. Points corresponding to the 'free' diet have not been graphed as the calorie intakes were not known with sufficient accuracy to justify their inclusion.

Fig. 4. Percentage change from the normal level in heat production $/ \mathrm{kg}$. body-weight of emaciated subjects (German group) during recovery, in relation to their calorie intake.

There is thus a possibility that the tendency for the heat production $/ \mathrm{kg}$. (or oxygen uptake $/ \mathrm{kg}$.) to decline in at least some of the subjects in the later phase of recovery might be due to a decreased demand for oxygen from the atmosphere. This decreased demand could be accounted for by supposing that oxygen-rich metabolites were being converted into oxygen-poor ones, thus rendering oxygen available for tissue oxidation. If this were so, deposition of fat must have been taking place. Clinical observation demonstrated conclusively, especially in the German subjects, that subcutaneous fat was being deposited. These subjects were receiving diets where total fat content did 
not exceed $100 \mathrm{~g}$. fat/week. In the Dutch group subcutaneous fat deposition occurred much more rapidly, as might have been expected on their higher calorie intakes.

We consider that our results for the later phase of recovery do not give an index of the level of basal metabolism. The apparent fall in the German group may be merely an index of the rate at which fat was being formed from oxygen-rich metabolites and not an indication that the tissues were in fact utilizing oxygen at a lower rate than normal. If observations of oxygen consumption alone are made, the levels of basal metabolism calculated from such data by assuming an R.Q. of 0.82 and a caloric value for oxygen of $4.825 \mathrm{Cal} . / 1$. may be misleading.

In another paper (Beattie \& Herbert, unpublished) we discuss the significance of respiratory quotients calculated from data obtained during the study of our Group I (Dutch) subjects.

\section{SUMMARY}

I. Twenty-two subjects who were emaciated after prolonged undernourishment were subjected to basal oxygen-consumption tests. The eleven subjects in the Dutch group were given their first test within $72 \mathrm{hr}$. of admission to hospital for treatment. The eleven subjects in the German group were tested on the 2nd or $3^{\text {rd }}$ day after the commencement of the first experimental diet period and after having been observed on a constant dietetic level of $175^{\circ} \mathrm{Cal}$./day for a period of 4-6 weeks.

2. The change in heat production $/ \mathrm{kg}$. body-weight, expressed as a percentage of the normal calculated rate of heat production, was proportional to the calorie intake, but not to the nitrogen intake, at the time of the first basal test.

3. When the calorie intake was approx. $35 \mathrm{Cal} / \mathrm{kg}$./day the rate of heat production observed was normal at the time of the first basal test.

4. In the later basal tests the rate of heat production (and oxygen uptake) was not related to the calorie intake level.

5. The fall in oxygen uptake in the German group as the calorie intake was increased in the later diet periods may not have been due to a diminished rate of oxygen utilization in the tissues but may have been related to the conversion of oxygen-rich into oxygen-poor metabolites.

We wish to thank our Dutch and British colleagues whose co-operation enabled us to collect the data recorded here from the Dutch group, and especially Miss A. W. Watts who was responsible for the dietetic work. We owe our thanks to Col. Pirrie and Brig. W. Strelley Martin, of the Public Health Branch of the Control Commission for Germany, for giving us the opportunity and facilities to undertake the German part of this work. The Council of the Royal College of Surgeons of England permitted us to carry out these investigations and allowed us to transport to Holland and Germany the necessary equipment from the College laboratories. They also granted permission for our two technical assistants to proceed overseas. The Medical Research Council provided funds to meet the expenses of the work. We wish to thank Miss E. M. Beattie for her assistance in checking our calculations. 
Beattie, J. \& Herbert, P. H. (1947). Brit. F. Nutrit. I, 185.

Boothby, W. M. \& Sandiford, I. (1929). Amer. F. Physiol. 90, 290.

Burger, G. C. E., Sandstead, H. R. \& Drummond, J. (1945). Lancet, 249, 282.

Du Bois, D. \& Du Bois, E. F. (1916). Arch. intern. Med. 17, 865.

Du Bois, E. F. (1936). Basal Metabolism in Health and Disease, 3rd ed. London: Baillière, Tindall and Cox.

Lusk, G. (1928). The Elements of the Science of Nutrition, 4th ed., p. 65. Philadelphia and London: W. B. Saunders Co.

\title{
Nitrogen Balances during Recovery from Severe Undernutrition
}

\author{
By J. BEATTIE and PHILIPPA H. HERBERT (Leverhulme Scholar) \\ Bernhard Baron Research Laboratories, Royal College of Surgeons of England, \\ Lincoln's Inn Fields, London, W.C. 2 \\ AND D. J. BELL, Biochemical Laboratory, Cambridge
}

(Received 3× fuly 1947)

The results reported below were obtained on two groups of subjects, Group I in Western Holland in 1945 and Group II in the British Zone of Germany in 1946. Among the objects of the Dutch investigation was the determination of the calorieand protein-intake levels which would secure optimum nitrogen retention and rapid increase in weight in severely undernourished patients. The later work in Germany had as one of its objects the determination of the calorie and protein-nitrogen intakes necessary to secure nitrogenous equilibrium in subjects who were considerably wasted. They had lived on diets low in calories and protein over a period of about I year and were in slight negative nitrogen balance when first observed.

\section{METHODS}

The calorie and nitrogen contents of the daily intakes were estimated from food tables; for foodstuffs of British origin McCance \& Widdowson's (1942) tables were used. These were supplemented by values given by the Council of British Societies for Relief Abroad (1945) which contained more up-to-date information on wartime foods and especially on those of American origin. A third set of tables prepared by the Netherlands Food Administration (1944) during the German occupation was of great value in determining the composition of foodstuffs of Dutch origin, such as bread baked from locally produced flour, wartime cheeses and certain vegetables not included in the previous tables. Owing to the variations in the proportions of the cereals used in preparing the flour used for bread-and biscuit-making in Holland and for bread-making in Germany, it was necessary to carry out periodical analyses to 